\title{
Fora do currículo há Educação? 0 projeto de extensão for a da sala de aula: suas formações e suas práticas educativas não escolares em São
}

Gonçalo.

Is there Education out of the curriculum? The extension project outside the classroom: its formations and non-school educational pratictices at São Gonçalo.

Autor

Arthur Vianna Ferreira. Departamento de Educação DEDU

Faculdade de Formação de Professores de São Gonçalo FFP

Universidade do Estado do Rio de Janeiro - UERJ.

E mail: arthuruerjffp@gmail.com

Recebido em: 14/08/2016 Aprovado em: 20/05/2017

DOl: 10.12957/interag.2017.25096

\section{Relato}

Este relato de experiência tem como objetivo partilhar as ações extensivas realizadas no primeiro semestre de 2016 pelo projeto de extensão "Fora da sala de aula: Formações, Representações e Práticas educativas não escolares e/ou extracurriculares no município de São Gonçalo" na Faculdade de Formação de Professores da UERJ em São Gonçalo. Este projeto, em andamento, tem como objetivos gerais investigar as práticas educativas não formais desenvolvidas por instituições socioeducacionais e coletivos de profissionais da educação que atuam com projetos extracurriculares desenvolvidos junto às camadas empo-

\section{Abstract}

This research explains the extensive actions of the extension project "Outside the Classroom: Formations, representations and non-school educational practices in São Gonçalo" at the Rio de Janeiro State's University (UERJ) on this city. This project is at development and investigate the non-formal educational practices from the social institutions of education that work with extracurricular projects developed by the poor people of São Gonçalo. As well, this project promotes the continued training education for the professionals' responsible for the educational works of these non-school programs or extracurricular activities in 
brecidas do município de São Gonçalo, assim como promover a formação continuada dos profissionais da educação responsáveis pelo trabalho pedagógico desses espaços não escolares e/ou atividades extracurriculares realizadas em escolas e a inserção dos graduandos de pedagogia nesses espaços socioeducacionais de atuação profissional através da extensão universitária. Dessa forma, essas ações extensionistas possibilitam aos seus participantes o diálogo com a experiência, a construção e a presença dos saberes desses profissionais da educação nos distintos espaços educativos e sociais da escola. Os encontros entre educadores sociais, professores e graduandos possibilitam uma discussão sobre as práticas educacionais não formais, a formação inicial e continuada dos profissionais da educação e a aproximação dos graduandos de pedagogia - e outras licenciaturas - às práticas educacionais não escolares, verificando as possíveis e distintas atuações dos futuros pedagogos e/ou licenciados nos espaços não escolares e suas rotinas, suas práticas e suas representações socioeducacionais.

Palavras-chave: Ações extensionistas. Educação não escolar. Licenciaturas. Formação docente.

Área temática: Educação

Linha de extensão: Formação de professores, Grupos sociais vulneráveis, Metodologias e estratégias de ensino/ aprendizagem. schools. Those actions seek the integration of the university students at these social and educational fields of professional activities through the university extension. The extension actions allow the participants show their experiences. The presence of knowledge of these professionals of education in different social spaces helps at the construction of the new training spaces at university. The meetings between social educators, teachers and graduate students allow a discussion of the non-formal educational practices and the training of education professionals and the university's students. The organization of this extension action promotes possibilities of new and distinct pedagogues' actions in non-school spaces and everyday routines as their practices and their socio-educational representations.

Keywords: Extension actions. Non-school education. Graduation. Training teacher. 


\section{Introdução}

\section{0 que é o projeto de extensão "Fora da sala de aula"?}

O projeto de extensão Fora da Sala de Aula é constituído a partir da premissa de que todos os espaços sociais são, potencialmente, campos de relações pedagógicas e de rotinas educacionais1. Ou seja, as relações entre os grupos sociais são intermediadas por constantes relações de cunho pedagógico - não escolares- que, estabelecidas entre seus indivíduos, se constituem em um ambiente de relações psicossociais importantes para identidade dos indivíduos, suas atribuições e suas pertenças, dentro e fora de seus grupos sociais.

Assim sendo, as atividades propostas por esse projeto de extensão universitária ligado ao Departamento de Educação da Faculdade de Formação de Professores de São Gonçalo (FFP) busca, inicialmente, a promoção de trocas de experiências entre os sujeitos do campo educativo não escolar - ou de atividades extracurriculares - e os graduandos de pedagogia e licenciaturas, potencializando tanto a formação inicial dos futuros docentes quanto a construção de um espaço formativo de extensão universitária para os profissionais da educação não escolar ou de atividades extracurriculares em escolas que atendem às camadas empobrecidas do município de São Gonçalo. O fim dessas práticas está na possibilidade de (re)organização da identidade socioprofissional dos educadores em seus campos de trabalho sociopedagógicos e dos graduandos de pedagogia e licenciaturas da FFP nos diversos espaços extracurriculares e instituições socioeducativas na realidade social do município de São Gonçalo e adjacências.

\section{Por que um projeto de extensão para formação docente para espaços não escolares?}

A formação docente deve ser compreendida a partir da possibilidade de atendimento das demandas educacionais estabelecidas no seu tempo-espaço histórico e social. A docência nas instituições escolares, entendidas socialmente como instituições educacionais formais, é uma das principais atuações desse profissional, porém não pode ser considerada como a única em relação às demandas sociais colocadas a esse profissional da educação na sociedade contemporânea brasileira.

Essa realidade concreta da formação deste profissional se encontra contemplada nas Diretrizes Curriculares Nacionais para o curso de graduação em Pedagogia, de 15 de maio de 20062. Esta esclarece que as atividades docentes para as quais esse profissional está sendo formado são compostas das habilidades de planejar, executar, coordenar, acompanhar e avaliar projetos e experiências educativas não escolares conforme disposto no artigo $4 \$ 42$. Ao mesmo tempo, no artigo $5 \$ 6$ do documento expõe a necessidade formativa para esse futuro pedagogo de "trabalhar, em espaços escolares e não escolares, na promoção da aprendizagem de sujeitos em diferentes fases do desenvolvimento humano, em diversos níveis e modalidades do processo educativo" 2 . 
Da mesma forma, o artigo 6 §1a, as diretrizes recordam que os cursos de pedagogia deverão, também, preparar estes sujeitos para as atuações já descritas nos artigos e parágrafos anteriormente citados como também para o cumprimento da contribuição social do curso, que é o "desenvolvimento das pessoas, das organizações e da sociedade."2

Esta discussão sobre a formação dos profissionais de educação em ambientes escolares e não escolares continua nas Diretrizes Curriculares Nacionais para a formação inicial em nível superior (cursos de licenciatura, cursos de formação pedagógica para graduados e cursos de segunda licenciatura) e para a formação continuada de 1ำ de julho de 20153.

No artigo 3 \$1 sobre a formação inicial e continuada o documento conceitua a concepção de educação inferindo que "por educação entendem-se os processos formativos que se desenvolvem na vida familiar, na convivência humana, no trabalho, nas instituições de ensino, pesquisa e extensão, nos movimentos sociais e organizações da sociedade civil e nas relações criativas entre natureza e cultura"3

Assim, por mais que a resolução seja contextualizada para a formação do ensino básico, no conjunto dos parágrafos deste mesmo artigo, entende-se o reconhecimento da necessidade do diálogo entre a educação formal escolar e os diversos espaços sociais onde a educação é realizada para que ela se realize de forma plena. Na verdade, o ambiente social e suas demandas institucionais estão em constante diálogo com os contextos escolares formativos em que atuarão os futuros pedagogos.

Por isso, o documento reafirma uma postura já existente na antiga resolução de 20062 em seu art. 12 \$1 d. sobre a formação inicial do docente, que, além dos processos educativos escolares, também deverá ser apto para "observação, análise, planejamento, desenvolvimento e avaliação de processos educativos e de experiências educacionais em instituições educativas", abrindo uma compreensão para outros espaços educativos não escolares. Além disto, as novas diretrizes no capítulo VII, art 18 \$3 reconhecem a valorização do magistério e dos profissionais da educação, entendendo que a formação inicial e continuada, assim como suas condições de trabalho, devem ser garantidas para todos os profissionais envolvidos na ação educativa, seja no ambiente do magistério seja em outros ambientes e instituições que realizam práticas educativas.

A exposição das normas determinadas pelas legislações educacionais brasileiras se apresenta como relevante para a discussão sobre a articulação entre o ensino formal aquele conhecido como escolar - e o não formal - desenvolvido por espaços sociais não escolares. Os artigos presentes nessa fundamentação teórica se transformam em base para qualquer discussão realizada pelos autores da área da educação não escolar.

De fato, a legislação referenda a existência dessa prática como parte da nossa identidade enquanto docente de forma ampliada. Assim sendo, mesmo preocupada com o cumprimento do conjunto de disciplinas do currículo formal, nossa prática não deve excluir a liberdade proposta pela criatividade do "saber-fazer" da educação existente nas práticas em instituições não escolares.

O diálogo, iniciado na investigação no campo educacional não escolar de São Gonçalo e suas relações com a população empobrecida, estão sendo ampliados e organizados a partir do auxílio de teorias oriundas de três áreas das ciências humanas: a Educação, no campo teórico da Pedagogia Social 4 e da Educação Social5; a Psicologia Social, a 
partir da abordagem da Teoria das Representações Sociais6; e da Sociologia e educação , conforme os conceitos de Identidade Profissional em Dubar 7 e os saberes profissionais de Tardif 8. A articulação dessas teorias se realiza ao longo do desenvolvimento das atividades de forma a atender às demandas surgidas ao longo das ações extensionistas. Enfim, a legitimidade desse projeto se encontra no esforço de contribuir sobre a discussão local e nacional sobre a formação, inicial e continuada, dos pedagogos e dos profissionais da educação no curso de Pedagogia e/ou licenciaturas da UERJ/FFP, de maneira especial os que se encontram em ambientes não escolares.

\section{Quais os objetivos deste projeto, metodologia e os primeiros resultados deste projeto de extensão?}

Os objetivos gerais desse projeto são investigar as práticas educativas não escolares e/ ou extracurriculares desenvolvidas por instituições socioeducacionais e coletivos de profissionais da educação que atuam junto às camadas empobrecidas do município de São Gonçalo; e, promover a formação continuada, para os profissionais da educação responsáveis pelo trabalho pedagógico destes espaços não escolares e/ou extraclasse, e inicial para os graduandos do curso de pedagogia, através da inserção destes últimos na discussão sobre a atuação dos pedagogos e licenciados nos diversos campos socioeducacionais.

Para isso, estão sendo desenvolvidos os seguintes objetivos específicos:

a) Levantar as instituições, projetos e coletivos educacionais não escolares no município de São Gonçalo em relação a sua proximidade territorial e conceitual da Faculdade da Formação de Professores da UERJ.

b) Investigar sobre as práticas educativas e sociais construídas pelas/nas instituições mais significativas no atendimento à população empobrecida do município de São Gonçalo e adjacências.

c) Proporcionar formação continuada para os profissionais destas instituições não escolares e dos projetos extracurriculares nas escolas, assim como encontros formativos de diálogos, eventos e oficinas com os graduandos de pedagogia sobre a organização de práticas educativas e atuação dos pedagogos em instituições sociais e educacionais não escolares.

d) Fortalecer a identidade dos profissionais da educação nos campos não escolares e de projetos socioeducacionais, a partir de três ações principais: a discussão sobre suas práticas educativas e as situações de empobrecimento representadas na realidade psicossocial da educação não escolar; o debate sobre as demandas sociais específicas do município de São Gonçalo e as possibilidades de atuação dos pedagogos nessa realidade histórico-social; e a aproximação teórico-empírica dos profissionais da educação não escolar e projetos extracurriculares com a comunidade científica e universitária da FFP/UERJ.

A metodologia desenvolvida pelo professor-coordenador do projeto e seus alunos bolsistas é articulada em três etapas/movimentos extensionistas, nomeados como: 'interrogativo, reflexivo e admirativo'. Veja, no quadro abaixo, o desenvolvimento destas três etapas, dentro dos eixos de ensino, pesquisa e extensão, ao longo do primeiro semestre 


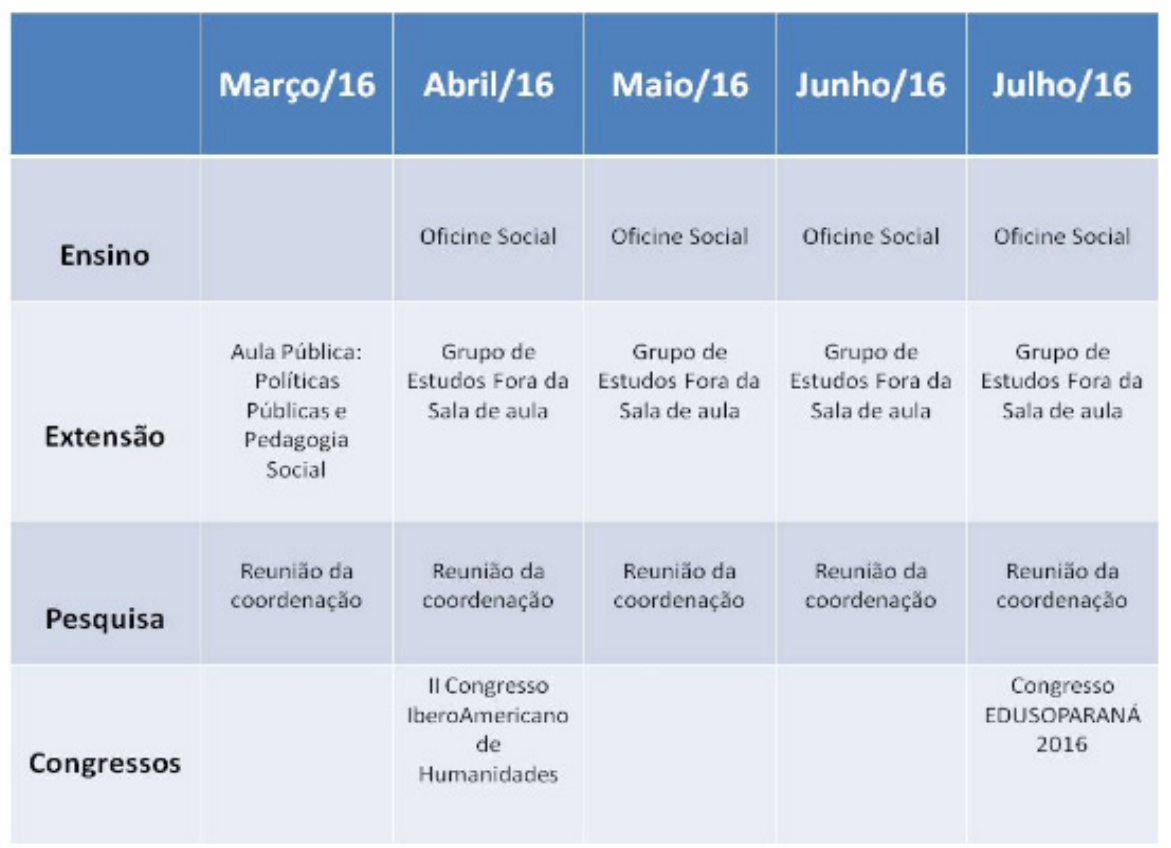

de 2016.

Quadro 1: Atividades desenvolvidas pelo Projeto de Extensão em 2016.1

A partir desse panorama, relata-se o desenvolvimento de cada uma das etapas e os resultados parciais obtidos nesse primeiro semestre de 2016.

3.1. Fora da sala de aula? (Movimento interrogativo: investigação das representações de pobreza nas práticas educativas)

Essa etapa do projeto de pesquisa se caracteriza pela investigação e levantamento das práticas educacionais realizadas com as camadas empobrecidas em espaços e projetos socioeducativos nos bairros do entorno da UERJ em São Gonçalo por parte do professor extensionista e alunos bolsistas.

Nessa primeira etapa, começada em março de 2016, o grupo está realizando o levantamento geográfico, urbano e social do Município de São Gonçalo, a partir do aprofundamento dos dados estatísticos oficiais produzidos pelo IBGE de 2010. Além disso, o grupo de extensão está concretizando uma investigação, e primeiro contato, com as instituições educacionais não escolares do município, averiguando a sua existência e continuidade dos seus trabalhos.

Os primeiros resultados dessa investigação constatam que das 38 instituições cadastradas oficialmente como Instituições de educação não escolar (não formal e informal) apenas 24 mantêm as suas atividades de maneira sistemática. Todas as demais possuem ações pontuais e não sequenciais ao longo do ano. Preliminarmente, a partir das indicações de Silva4 e Graciani5 sobre a natureza das práticas socioeducacionais classificou-se estas instituições segundo os três focos apresentados como área central de suas práticas socioeducativas junto às comunidades empobrecidas: a atuação sociopedagógica (09 instituições), a atuação sociocultural (02 instituições) e a atuação 
sociopolítica (13 instituições). Os estudos de investigação darão continuidade e aprofundamento a estas instituições para melhor compreensão de suas práticas educativas na realidade social de São Gonçalo. Da mesma forma, o grupo de extensão pretende expandir sua investigação para os municípios vizinhos de São Gonçalo, principalmente aqueles que possuem poucas referências sobre educação social e pedagogia social para que possamos entender como eles articulam estes conceitos para uma prática transformadora da realidade social.

O grupo de extensão também se propôs a realização de uma investigação histórica a respeito das práticas educativas junto às camadas empobrecidas da Região. Esta parte do trabalho está sendo realizado nos arquivos do jornal da cidade - "O São Gonçalo" - a partir de um levantamento das notícias sobre atendimento às camadas empobrecidas dos anos de 1930 até os dias atuais com o objetivo de compreender como os recursos midiáticos representavam os pobres da cidade e de que forma este discurso oficial de um determinado grupo de poder contribuiu para a construção do senso comum sobre práticas educativas com os pobres existentes até os dias atuais. Até o presente momento foram analisadas as décadas de 1930 a 1950. Os primeiros resultados desses trabaIhos investigativos estão sendo divulgados em congressos e seminários de educação ao longo do ano de 2016.

3. 2. Fora da sala de aula... (Movimento reflexivo: formação inicial e continuada dos profissionais da educação e os alunos de graduação)

Até o presente momento o projeto de extensão está organizando e promovendo encontros a partir de duas ações extensionistas específicas: o oficine social e o Grupo de Estudos Fora da Sala de Aula (GEFSA). Ambos envolvem os profissionais da educação das instituições e projetos sociais de São Gonçalo, os alunos graduandos de pedagogia e licenciaturas da UERJ e outras universidades privadas e a comunidade do entorno da Faculdade de Formação de Professores. Cada um desses encontros acontece uma vez ao mês e fortalecem os vínculos entre educadores sociais, professores e alunos nos grupos de discussão sobre educação para as camadas empobrecidas e a formação dos indivíduos para essa tarefa pedagógica. Faz-se necessário compreender cada uma das ações extensionistas e suas contribuições para a formação inicial ou continuada dos sujeitos da prática educativa.

O Oficine Social tem como objetivo refletir sobre as temáticas da pedagogia social a partir dos recursos audiovisuais como documentários, músicas, filmes entre outros. Os encontros são de duas horas onde, a partir das necessidades e reflexões levantadas pelo próprio grupo, o coordenador e os alunos bolsistas organizam as atividades para o grupo. Desta forma, ao mesmo tempo em que os graduandos e profissionais da educação social podem buscar sua formação inicial ou continuada a partir de suas necessidades, o grupo de extensão apreende as principais demandas de trabalho desse grupo e apreendendo quais os saberes profissionais 8 articulados nesse campo da educação não escolar existente no município de São Gonçalo.

Veja no quadro abaixo os temas trabalhados até o presente momento pelo grupo de 


\section{OFICINE SOCIAL}

\begin{tabular}{|c|l|l|}
\hline Mês & \multicolumn{1}{|c|}{ Tema } & \multicolumn{1}{|c|}{ Objetivo } \\
\hline Abril/Maio & $\begin{array}{l}\text { Educação escolar x educação } \\
\text { não escolar }\end{array}$ & $\begin{array}{l}\text { Compreender a educação } \\
\text { como práticas constitutivas } \\
\text { da realidade social }\end{array}$ \\
\hline Junho & $\begin{array}{l}\text { Eduççãox } \text { Instituições } \\
\text { familiares }\end{array}$ & $\begin{array}{l}\text { Refletir sobre as práticas } \\
\text { educacionais a partir da } \\
\text { mudança de paradigmas } \\
\text { sobre a familia }\end{array}$ \\
\hline Julho & Educaçãox Politica & $\begin{array}{l}\text { Entenderas relações } \\
\text { estabelecidas entre a } \\
\text { educaçãoe as micropoliticas } \\
\text { contemporâneas }\end{array}$ \\
\hline
\end{tabular}

extensão:

Quadro 2: Temas de formação continuada do OFICINE SOCIAL

O Grupo de estudos (GEPE) Fora da Sala de Aula objetiva o estudo dos principais conceitos da Pedagogia Social que buscam fundamentar as práticas socioeducacionais realizadas pelos educadores sociais, professores e alunos que atuam em rotinas de aprendizagem em ambientes não escolares. Esse grupo de estudo está aberto, também, a toda comunidade interna e externa da Faculdade de Formação de Professores e sua rotina e seu desenvolvimento se dá a partir do estudo de textos pré-selecionados pelo grupo que coordena a extensão. Esses textos estão disponibilizados em uma plataforma virtual chamada "Socializando Pedagogias" (www.socializandopedagogias.wordpress. com), disponível para todos os que se interessam pelas práticas socioeducacionais. $\mathrm{O}$ quadro abaixo mostra os temas e textos trabalhados até o presente momento. 


\begin{tabular}{|c|c|c|}
\hline GEFSA & & \\
\hline Mês & Texto & Objetivo \\
\hline Abril/Maio & $\begin{array}{l}\text { "Origens da Pedagogia } \\
\text { Social"- Hans Uwe Otto }\end{array}$ & $\begin{array}{l}\text { Estudar a construção do } \\
\text { campo teórico da pedagogia } \\
\text { social a partir do recorte } \\
\text { histórico do século XIX e XX e } \\
\text { seus principais autores. }\end{array}$ \\
\hline Junho & $\begin{array}{l}\text { "Pedagogia Social: A } \\
\text { formaçăo do Educador Social } \\
\text { e seu campo de atuaçāo"- } \\
\text { João Clemente Netto }\end{array}$ & $\begin{array}{l}\text { Compreender a pedagogia } \\
\text { social campo de estudos da } \\
\text { educaçăoe suas } \\
\text { contribuiçōes na formação } \\
\text { docente inicial. }\end{array}$ \\
\hline Julho & $\begin{array}{l}\text { "Pedagogia Social: seu } \\
\text { Potencial critico e } \\
\text { transformador " Geraldo } \\
\text { Caliman }\end{array}$ & $\begin{array}{l}\text { Potencializar os conceitos de } \\
\text { Pedagogia Social, seus limites } \\
\text { e seus beneficios nas práticas } \\
\text { educativas năo escolares. }\end{array}$ \\
\hline
\end{tabular}

Quadro 3: Temas e objetivos dos encontros de formação GEFSA

Os temas apresentados nos quadros acima são levantados pela coordenação do projeto a partir de atas e diários de campos realizados pelos alunos-bolsistas nos encontros e depois discutidos na reunião mensal do grupo de Pesquisa do Projeto. Essas ações extensionistas servem como atividades complementares para os alunos participantes e como subsídio para as disciplinas eletivas oferecidas pelo departamento de educação como Educação e Direitos Humanos, Psicologia Social e Psicomotricidade aos graduandos de licenciatura da Faculdade de Formação de Professores da UERJ. Dessa forma, a extensão se relaciona com a dimensão de ensino curricular dos cursos de formação de professores, completando o tripé científico que deve ser produzido pela universidade: ensino, extensão e pesquisa.

3.3. Fora da sala de aula! - (Movimento admirativo: re/nova prática com as camadas empobrecidas)

Esse projeto de extensão busca, também, em seus objetivos a produção de materiais e eventos sobre: a organização das práticas educativas não escolares e extracurriculares, os processos formativos de educadores para atuação nesse campo psicossocial e as relações psicossociais com as camadas empobrecidas atendidas por essas instituições e projetos socioeducativos.

Até o presente momento, o grupo que coordena a extensão se apresentou em alguns congressos fora do estado do Rio de Janeiro, tanto fortalecendo as parcerias com outros grupos que discutem a mesma temática como representam as práticas educativas estabelecidas na UERJ no campo teórico da Pedagogia Social que segue em construção no País. 
As avaliações desse projeto são realizadas de forma qualitativa e ao longo da realização das atividades tendo como referência a contribuição do trabalho de extensão ao tripé universitário: Ensino, Extensão e Pesquisa. No final do projeto de extensão também será realizado relatório a partir de questionários online e/ou presencial, a ser formulado posteriormente, e respondido pelos três sujeitos deste projeto: os profissionais da educação, os alunos de graduação e o professor-extensionista.

Os materiais produzidos por este projeto de extensão já estão disponíveis para consulta pública de forma online pelos sites: www.pedagogiasocialffp.wordpress.com,www. foradasaladeaulaff.wix.com/projex e socializandopedagogias.wordpress.com, alimentados ao longo do desenvolvimento do projeto de extensão.

Enfim, podemos entender que o Projeto de Extensão "Fora da Sala de Aula" ainda é um projeto em (re) construção realizado por professores, graduandos e profissionais da educação que buscam entender a realidade social como uma possibilidade de processos educativos de transformação do indivíduo e da sociedade.

Fora do currículo há educação! As práticas socioeducacionais mapeadas, aprofundadas e estudadas por este projeto de extensão tanto comprovam essa afirmativa quanto mostram a necessidade da Faculdade de Formação de Professores da UERJ pensar sobre o seu próprio currículo de formação docente, sobre a postura dos professores da unidade em trabalhar suas reflexões em suas disciplinas obrigatórias e eletivas em relação a esse campo de atuação dos licenciados e abrir a universidade pública para o que realmente importa: as necessidades do público historicamente constituído nessa realidade social de empobrecimento de São Gonçalo e regiões adjacentes.

\section{REFERÊNCIAS}

1. ARANTES,Valeria Amorim (org.) Educação formal e não formal. São Paulo: Summus, 2008.

2. BRASIL. Resolução CNE/CP no 1, de 15 de maio de 2006. Institui Diretrizes Curriculares Nacionais para o Curso de Graduação em Pedagogia. Diário Oficial da República Federativa do Brasil, Poder Executivo, Brasília, DF, 17 mai. 2006.

3. BRASIL. Resolução CNE/CP no 2, de 1․ de julho de 2015. Define as Diretrizes Curriculares Nacionais para a formação inicial em nível superior (cursos de licenciatura, cursos de formação pedagógica para graduados e cursos de segunda licenciatura) e para a formação continuada. Diário Oficial da República Federativa do Brasil, Poder Executivo, Brasília, DF, 04 jul. 2015.

4. SILVA, Roberto da; SOUZA NETO, João Clemente; MOURA, Rogério. (Orgs.) Pedagogia Social. São Paulo: Expressão e Arte Editora, 2011.

5. GRACIANI, Maria Stela. Pedagogia Social. São Paulo: Cortez, 2014.

6. DOISE, Willem. Atitudes e representações sociais. In: JODELET, Denise. (Org.) As representações sociais. Rio de Janeiro: EdUERJ, 2001.p. 187-204.

7. DUBAR, Claude. A socialização - Construção das identidades sociais e profissionais. São Paulo: Martins Fontes, 2005.

8. TARDIF, Maurice. Saberes docentes e Formação profissional. Petrópolis: Vozes, 2002. 